\title{
Sensibilidade e especificidade do auto-exame das mamas em relação ao seu exame clínico, numa população de funcionárias de um hospital universitário de Fortaleza
}

Sensibility and specificity of the breast self-examination in relation to its clinical examination, in a population of university hospital employees of Fortaleza

Aluno: Francisco Alberto Régio de Oliveira

Orientador: Prof. Dr. Luiz Gonzaga Porto Pinheiro

Dissertação de Mestrado, apresentada à Coordenação do Curso de Pós-Graduação em Tocoginecologia, da Universidade Federal do Ceará - UFC - Fortaleza CE) - Brasil em 22/12/04.

Objetivo: verificar a freqüência dos conhecimentos e práticas relacionadas com o auto-exame das mamas (AEM). Estimar a sensibilidade e especificidade do AEM em relação ao seu exame clínico (EC). Averiguar se a sensibilidade é influenciada pelas variáveis antropométricas, sociodemográficas, conhecimentos e práticas do AEM. Método: estudo transversal de validação de teste diagnóstico, envolvendo 505 funcionárias de um hospital universitário. Foi aplicado questionário sobre conhecimentos e práticas relacionadas com AEM, ministrada instrução sobre AEM as participantes que posteriormente realizaram AEM e foram submetidas a EC por único examinador. Os intervalos de confiança de $95 \%$ foram calculados pelo método de aproximação pela distribuição normal. Proporções foram comparadas através do teste do qui-quadrado e foram consideradas significativamente diferentes (teste bicaudado) quando a probabilidade de serem semelhantes foi $\leq 0,05$. Resultados: $94,0 \%$ tinham recebido informação sobre o AEM, 29,9\% por médico. 32,2\% realizavam AEM mensalmente, $55,9 \%$ após a menstruação e o procedimento mais realizado era a palpação durante o banho. A sen- sibilidade para qualquer achado foi 37,21\% (IC95\% = $32,7 \%-41,82 \%)$. A sensibilidade, excluindo-se a assimetria, foi 44,8\% (IC95\% = 39,5-50,26\%). A sensibilidade exclusiva para nódulo e espessamento (massa) foi 52,0\% (IC95\% = 43,17\%-60,8\%). A especificidade para qualquer achado foi $71,64 \%(\mathrm{IC} 95 \%=60,0 \%-81,4 \%)$. A especificidade, excluindo-se a assimetria, foi $80,5 \%$ (IC95\% = 74,2\%-85,93\%). A especificidade exclusiva para massa foi 90,10\% (IC95\% = 86,8\%-92,79\%). A sensibilidade não mostrou diferença estatisticamente significativa quando estratificada por mama, conhecimentos e práticas relacionadas ao AEM e variáveis antropométricas e sociodemográficas. Conclusão: o AEM é bastante conhecido por essa população, apresenta em relação ao EC uma baixa sensibilidade e especificidade, que eleva-se quando analisadas exclusivamente as massas, aproximando-se da sensibilidade e especificidade da mamografia em mulheres abaixo dos 40 anos.

PALAVRAS-CHAVE: Neoplasias mamárias - prevenção e controle; Auto-exame de mama; Sensibilidade e especificidade; Rastreamento do câncer

Resumo de Tese

\section{Atividade da aromatase em células da granulosa de mulheres com endometriose submetidas a técnicas de reprodução assistida}

\section{Aromatase activity in granulosa cells of women with endometriosis undergoing assisted reproduction techniques}

Autor: Lauriane Giselle de Abreu

Orientador: Prof. Dr. Marcos Dias de Moura

Dissertação de Mestrado apresentada à Faculdade de Medicina de Ribeirão Preto, Universidade de São Paulo - USP Ribeirão Preto (SP) - Brasil, para obtenção do título de Mestre em Medicina na área de concentração de Tocoginecologia., em 31 de maio de 2005.

A associação endometriose-infertilidade é inequívoca, entretanto, os mecanismos envolvidos ainda permanecem não esclarecidos e aberrações moleculares emergem como possiveis alvos de defeitos. Acredita-se em comprometimento poligênico com alterações de citocinas e enzimas da esteroidogênese como a aromatase. Esta é responsável por transformar andrógenos em estrógenos e na granulosa é essencial para a foliculogênese. $\mathrm{Na}$ endometriose, foram encontradas alterações da aromatase em implantes endometrióticos e endométrio tópico, além de redução de sua atividade na granulosa, com possível comprometimento da qualidade oocitária. Objetivo: medir a atividade da aromatase nas células da granulosa in vitro de mulheres com endometriose submetidas à reprodução assistida. Métodos: caso-controle, 8 pacientes com endometriose e 8 com outras causas de infertilidade sub- metidas à FIV ou ICSI. Coletaram-se células da granulosa de folículos pré-ovulatórios e realizou-se cultivo celular por 24 horas, na presença ou não de testosterona a $2 \times 10^{-6} \mathrm{M}$ e 2 x $10^{-5} \mathrm{M}$; FSH e IGF-1 (50 ng/ml). Posteriormente, foram dosados estradiol (radioimunoensaio) e progesterona (quimioluminescência) nos fluidos de cultivo. Resultados: houve redução da atividade da aromatase nas células da granulosa na endometriose em relação ao controle, quando adicionada testosterona na concentração de $2 \times 10^{-6} \mathrm{M}$ $(p=0,0303)$. A produção basal de estradiol também foi reduzida na endometriose. A adição de FSH e IGF-1, bem como a produção de progesterona, não mostraram diferenças entre os grupos.

PALAVRAS-CHAVE: Aromatase; Endometriose; Células da granulosa; Reprodução assistida 